Annals of Glaciology $3 \quad 1982$

(C) International Glaciological Society

\title{
SEASONAL VARIATIONS IN THE SURFACE ENERGY EXCHANGES OVER ANTARCTIC SEA ICE AND
} COASTAL WATERS

by

\author{
I. Allison, C. M. Tivendale, G. J. Akerman, J. M. Tann and R. H. Wills \\ (Antarctic Division, Kingston, Tasmania 7150, Australia)
}

\section{ABSTRACT}

Seasonal variations in radiative and turbulent fluxes at the surface of, and in the heat transfer within, sea ice are discussed from results of energy balance studies at a site of annual ice cover near Mawson, Antarctica. In mid-summer, the open water gains heat mostly by radiation but by early February the ocean is cooling predominantly by strong turbulent losses, with some radiative heat loss occurring also by March. When an ice cover forms, turbulent fluxes decrease from several $100 \mathrm{~W} \mathrm{~m}^{-2}$ over open water to only $40 \mathrm{~W} \mathrm{~m}^{-2}$ over ice less than $0.2 \mathrm{~m}$ thick and even less over thicker ice. Net radiative losses over mature ice in mid-winter are balanced mostly by conduction through the ice cover but with some turbulent heat gain at the surface. By midspring, there is a net radiative gain, the turbulent fluxes are again outgoing, and there is little total heat transfer through the ice. At break-out, the albedo increase from ice to open water causes a large increase in the net radiative gain.

At the lower boundary of the ice, the oceanic heat flux provides an important contribution. A net advection of heat into the region is shown from temperature profiles in the water under the ice. Salinity changes in the water during the period of ice melt are also discussed.

\section{INTRODUCTION}

Sea ice is the most variable of the southern hemisphere cryospheric elements in both seasonal extent and in interannual variation of concentration and distribution. As such, sea ice is considered to be an important element in southern hemisphere weather and short-period climate change. Ackley (1981) reviews much of the recent work on sea-ice/weather relationships.

The interaction between the ocean and the atinosphere is partly a function of the surface energy balance, and the importance of sea-ice variations is in the large differences in surface energy balance between open water, new ice, and thick ice. Compared to the Arctic, there are very few data on the surface energy balance of Antarctic sea ice, and what data are available come from a relatively narrow coastal zone of mostly shore-fast ice. Weller (1980) stresses the lack of data for the larger pack-ice zone, the region likely to have the greatest effect on the overall south-polar energy budget. In this zone, the ice cover is not continuous and the energy budget is influenced by both the sea-ice dynamics and thermodynamics.

However, the pack-ice zone is logistically difficult to study in detail compared to the shorefast ice. Data on the seasonal variation of the energy balance of fast ice can, however, provide information on the relative importance of various energy-exchange processes for various categories of ice thickness and type. Together with the limited data available from studies of open leads in the Arctic (Andreas and others 1979; Andreas 1980), this gives a background against which the various thermodynamic and dynamic models of sea ice (e.g. Parkinson and Washington 1979, Hibler 1980) can be tested.

In this paper, we summarize some of the seasonal changes that occur in the energy balance of shorefast sea ice and open water. The data discussed cone from a region of coastal seasonal ice cover near Mawson station, Antarctica $\left(67^{\circ} 36^{\prime} \mathrm{S}, 62^{\circ} 52^{\prime} \mathrm{E}\right)$. The energy balance of the sea ice at this site has been studied in 1965 (Weller 1968), 1969, and the period 1976 to 1980 , and some details of the field measurements are given by Allison and Akerman (1980). The experimental site is only about 200 in offshore, and subject to prevailing offshore katabatic winds. A sea-ice cover usually forms at the site in late March or early April and, after occasional early break-outs, usually remains stable from about May until the final break-out of the seasonal cover in Tate December to mid-January. The sed ice typically reaches a maximum thickness of 1.6 to $1.8 \mathrm{~m}$. Water depth at the main experimental site is about $150 \mathrm{~m}$ while, at a nearby site, where regular measurernents of the water structure under the ice were inade, the depth was over $300 \mathrm{~m}$.

The energy balance at the ice-atmosphere boundary can be expressed as

$$
N=\left(H+L_{S} E\right)+\left(B_{u}+I_{U}\right) \text {, }
$$

where $N$ is the net radiation $=G(1-\alpha)+L_{i}-L_{e}$ ( $G$ being the short-wave global radiation, $L_{i}$ the incoming long-wave radiation, Le the 1 ong-wave radiation enitted by the ice surface, and $\alpha$ the short-wave albedo), ( $H$ and $L_{s} E$ ) are the turbulent heat transfers ( $H$ being the sensible heat transfer and $L_{s} E$ the latent heat transfer associated with the sublimation of a mass of ice $E$ at the upper boundary), and $\left(B_{u}+I_{u}\right)$ are the energy transfers into the ice ( $B_{u}$ being the conducted heat flux at the upper boundary 
and $I_{u}$ the flux of short-wave radiation which passes through the surface into the interior of the ice).

Throughout this paper, we adopt the sign convention that a gain of net radiation by the surface is positive, while, for the other components, a flux away from the surface is positive.

The energy balance at the ice-ocean boundary is $L_{F} M+B_{L}+Q=0$, where $L_{F} M$ is the latent heat involved in freezing or melting a mass of ice $M$ at the lower boundary, $B_{\mathrm{L}}$ is the conducted heat flux at the lower boundary, and $Q$ is the turbulent transfer of heat between the ice and the ocean.

We consider here the seasonal changes of the radiative fluxes, the turbulent fluxes, and the energy transferred through the ice before briefly discussing the overall energy balance. We also consider the energy balance and interactions at the ice-ocean interface. There are large differences between the surface energy balance over ice and over open water, and these differences are most relevant when considering the impact of leads and polynyas in the pack ice on the total ocean-atmosphere heat exchange. Hence we emphasize the data showing changes in the energy balance as the ice first forms and when it finally breaks out.

\section{RADIATION FLUXES}

The formation of the sea-ice cover is marked by a rapid increase in surface albedo and hence a decrease in absorbed short-wave radiation. Allison and Akerman (1980) measured typical values of open-water albedo at the Mawson site of around 0.07 , al though in cloudless conditions, and at low sun angles, the albedo was over 0.15 . When the ice forms, usually in late March to early April, it initially grows rapidly, reaching $0.1 \mathrm{~m}$ thickness in about $2 \mathrm{~d}$ and $0.2 \mathrm{~m}$ in 4 to $5 \mathrm{~d}$. The surface albedo also increases rapidly froin the 0.07 open-water value to around 0.45 over $0.2 \mathrm{~m}$ ice (Allison 1973). Weller (1972), in a study of refreezing Arctic leads, gives a value of 0.20 for the albedo of ice only $0.03 \mathrm{~m}$ thick, and 0.35 for $0.2 \mathrm{~m}$ thick ice.

Despite the rapid increase of albedo, the overall change in net all-wave radiation is not large at the time of ice formation. This is partly because the ice cover forms at a time when short-wave radiation fluxes are sinall and are decreasing rapidly, and partly because the decrease in absorbed short-wave radiation is offset by a decrease in out-going longwave radiation. Figure 1 shows a typical annual cycle of the short-wave and net radiation fluxes, and the surface albedo, at the sea-ice site at Mawson.

observations over several seasons showed that the gain of net radiant energy by the open water is at a maximum (about $200 \mathrm{Wm}^{-2}$ average) in mid-January immediately after the break-out of the previous season's ice. The mean net radiation gain of the open water has decreased to zero by mid-March, and in early April, just prior to ice formation, the net radiative loss is on average $50 \mathrm{~W} \mathrm{~m}^{-2}$. In comparison, the average net radiative loss of $0.2 \mathrm{~m}$ thick new ice in early April was measured as $55 \mathrm{~W} \mathrm{~m}^{-2}$ (Allison 1973). Prior to ice formation the average energy gain from absorbed short-wave radiation was about $40 \mathrm{~W} \mathrm{~m}^{-2}$, which decreased to $25 \mathrm{~W} \mathrm{~m}^{-2}$ as the albedo increased. However the net loss of 1 ong-wave radiation was reduced from $90 \mathrm{~W} \mathrm{~m}^{-2}$ over water to $80 \mathrm{~W} \mathrm{~m}^{-2}$ over new ice as the surface temperature cooled from $-1.8^{\circ} \mathrm{C}$ to a value closer to the air temperature of $-15^{\circ} \mathrm{C}$. Holmgren and Weller (1974) similarly found little variation in the net radiative loss between leads and pack ice in the Arctic. Their estimates, for a period near to the spring equinox, give a net loss from the open lead of $77 \mathrm{~W} \mathrm{~m}^{-2}$, and from pack ice of $70 \mathrm{~W} \mathrm{~m}^{-2}$. The diurnal variation of net radiation over the open water, however, shows large amplitudes because of the lower albedo.

The albedo of the bare ice continues to increase to about 0.6 as the cover thickens, al though for most of the winter the albedo is around 0.8 and is largely influenced by a thin snow cover on the ice. However, during the winter, short-wave radiation is negligible and the net radiative loss from the sea ice remains fairly constant at about $50 \mathrm{~W} \mathrm{~m}^{-2}$. During mid-winter, the net radiative loss from the sea ice is $20 \%$ greater than from the nearby plateau ice with a lower radiating temperature (Weller 1968).
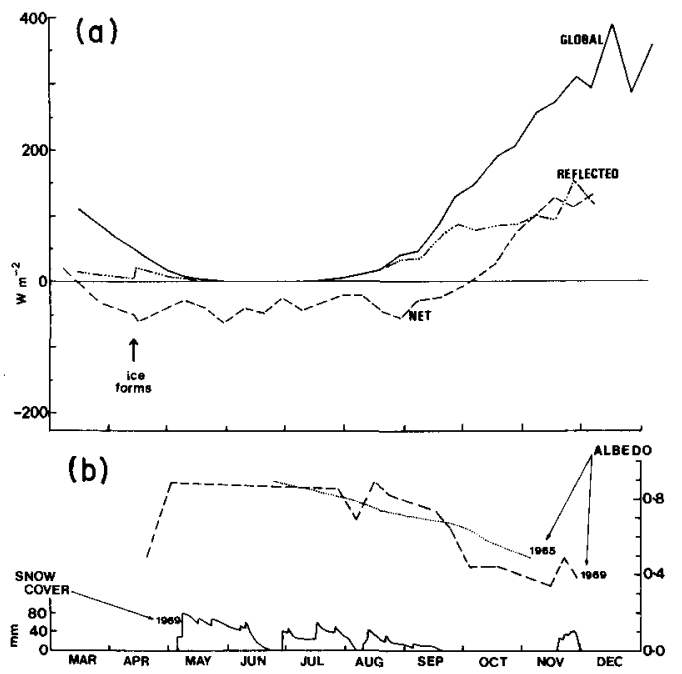

Fig.1. (a) 10-day mean short-wave (global and reflected) and net all-wave radiation fluxes over open water and fast ice near Mawson (1969). (b) Short-wave albedo of the fast-ice cover (1965 and 1969).

The net radiative loss slowly decreases, as the incoming short-wave radiation increases, and becomes zero in mid-October. The albedo starts to decrease at about the same time due to ablation and deterioration of the ice surface. Figure 1 shows a lower albedo in 1969, with a bare ice surface, than in 1965 when there were several millimetres of snow on the surface: small albedo changes at this period, when the available short-wave energy is increasing, can significantly affect the overall energy balance. Albedo measurements at Mawson, made with instruments suspended from a wire between towers (similar to the technique described by Langleben (1969)), confirm that the albedos shown in Figure $1(b)$ are representative of values over larger areas. The sea-ice surface does not become extensively puddied, as in the Arctic possibly because, due to greater wind speed and lower humidity in the Antarctic, turbulent transfer removes radiative energy that would otherwise be available for surface melting (Andreas and Ackley in press). Radiation absorption within the snow-free ice, however, causes internal melt, and the ice cover becomes rotten and dark in colour.

The average net radiative gain over the sea ice, even in mid-summer, is only about $100 \mathrm{~W} \mathrm{~m}^{-2}$, but as soon as the ice breaks out, the decrease of albedo to 0.07 leads to an increase in the radiation budget of the surface to about $+200 \mathrm{~W} \mathrm{~m}^{-2}$. At this time of year, it is the short-wave radiation which dominates changes; there is little difference in the long-wave balance between the decaying ice and open water, because surface temperatures are similar for both.

\section{TURBULENT FLUXES IN THE ATMOSPHERE}

The turbulent heat fluxes over open water are large and also show a large diurnal variation. For a few weeks in January, the water may gain heat by sensible transfer from the atmosphere for the greater part of the day, but as the season progresses, the period of sensible heat transfer to the water is 


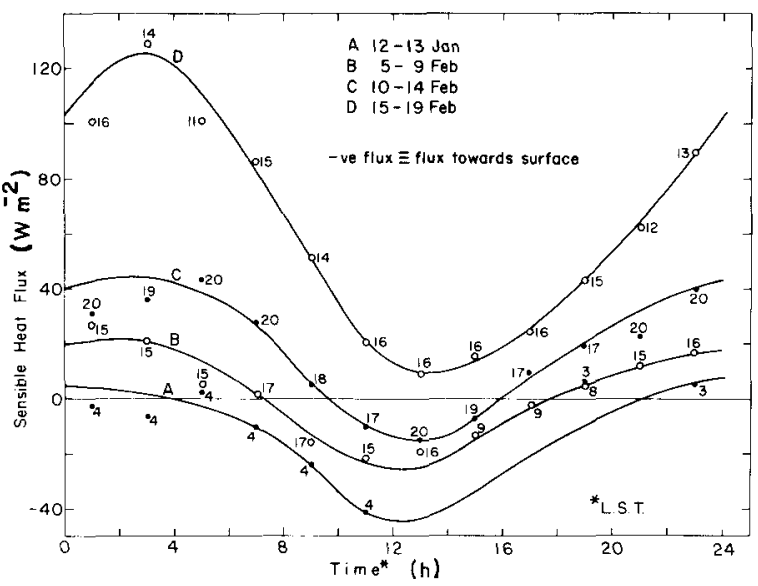

Fig.2. Diurnal variation of sensible heat flux over open water for various periods prior to ice formation (after Allison and Akerman 1980). (Copyright 1980, University of Washington Press.)

limited to a few hours around noon (Fig.2) (Allison and Akerman 1980). By mid-February, the surface loses sensible heat throughout the day and the mean loss can be up to $100 \mathrm{Wm}^{-2}$.

The turbulent transfer of latent heat is difficult to measure directly in the Antarctic because of the low levels and even sinaller gradients of water vapour in the air. In March 1980, however, we measured the effective increase of atmospheric moisture as air flows from the edge of the continental ice sheet over the ice-free ocean. In a light aircraft, we followed a flight path parallel to the wind direction at several different elevations up to $280 \mathrm{~m}$ while continuous measurements were made of humidity and temperature. Humidity was measured with a thin-film capacitive sensor (Vaisala Humicap), and temperature with a thermistor whose time constant was matched to the humidity sensor. The flight took place in mid-afternoon, with a mean surface air tempeature of $-4.3^{\circ} \mathrm{C}$, relative humidity of $60 \%$, and an average wind speed of $3 \mathrm{~m} \mathrm{~s}^{-1}$ up to $300 \mathrm{~m}$ elevation.

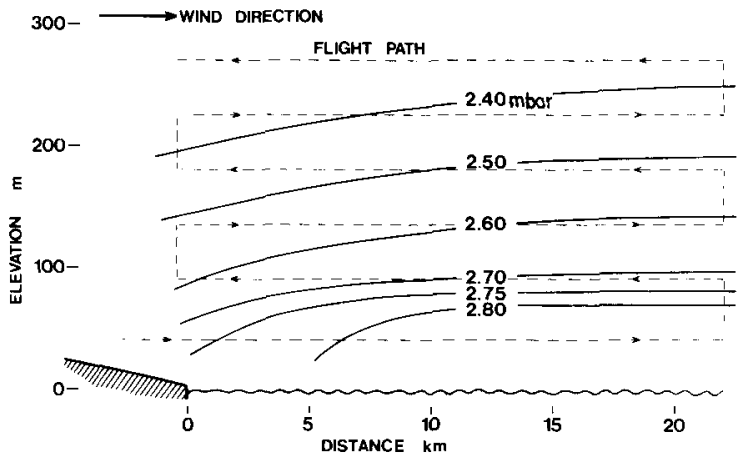

Fig.3. Increase in atmospheric moisture due to evaporation from open water downwind from the ice edge

( 3 March 1380). Values are of water vapour pressure in inbar.

Figure 3 shows the increase in the water vapour content of the air downwind of the ice edge. This increase occurs because of evaporation from the open water, and we can estimate the mean rate of evaporation from Figure 3 . In the first $10 \mathrm{~km}$, the total water-vapour increase in a column of water $1 \mathrm{~m}$ square ani $300 \mathrm{~m} \mathrm{high}$ is $18 \mathrm{~g}$. The latent hedt required to cvaporate this is $45 \mathrm{~kJ}$, so with a wind speed of $3 \mathrm{~ms}^{-1}$, the average turbulent latent heat tranfer over the first $10 \mathrm{~km}$ is $13.5 \mathrm{~W} \mathrm{~m}^{-2}$. From 10 to
$20 \mathrm{~km}$ downwind from the ice edge, the evaporation rate is less, only $4 \mathrm{~g} \mathrm{~m}^{-2}$ increase in water vapour, or an average heat transfer of $3 \mathrm{~W} \mathrm{~m}^{-2}$.

Similarly, from the temperature measurements alone, we can estimate the turbulent sensible heat transfer from water to the atmosphere. In the first $10 \mathrm{~km}$, the average air temperature of the column warmed by $0.11^{\circ} \mathrm{C}$, implying an average heat transfer of $13 \mathrm{~W} \mathrm{~m}^{-2}$. This rate remained nearly the same for the 10 to $20 \mathrm{~km}$ interval.

The heat transfers calcuiated by this method are considerably lower than those given by Allison (1973) or Allison and Akerman (1980), but the mean wind speed during the in-flight measurements was only $3 \mathrm{~m} \mathrm{~s}^{-1}$, compared to mean winds of over $10 \mathrm{~m} \mathrm{~s}^{-1}$ for the earlier studies. In all cases, however, the total turbulent heat transfer is shared approximately equally between latent and sensible heat. Over Arctic leads, with air temperatures below $-20^{\circ} \mathrm{C}$, Andreas and others (1979) measured correspondingly greater turbulent fluxes and also found the sensible heat transfer to be 2 to 5 times greater than the latent heat. The latter is a result of the strong dependence of saturation specific humidity on temperature. A similar result can be seen from the model calculations of Maykut (1978): the ratio of sensible heat to latent heat transfer over open water increases from 2 prior to normal freeze-up, to over 4 in late winter.

With the strong turbulent heat losses, the water cools from around $0^{\circ} \mathrm{C}$ at the end of January to $-1.8^{\circ} \mathrm{C}$ (the freezing point) in mid-March. Although pancake ice can form at this time, the formation of a stable sea-ice cover at Mawson requires fairly calm conditions. Preliminary data from drifting data buoys (A11ison and Morrissy in press) show that $300 \mathrm{~km}$ further north the rate of water cooling parallels that near ilawson but takes place about $45 \mathrm{~d}$ later.

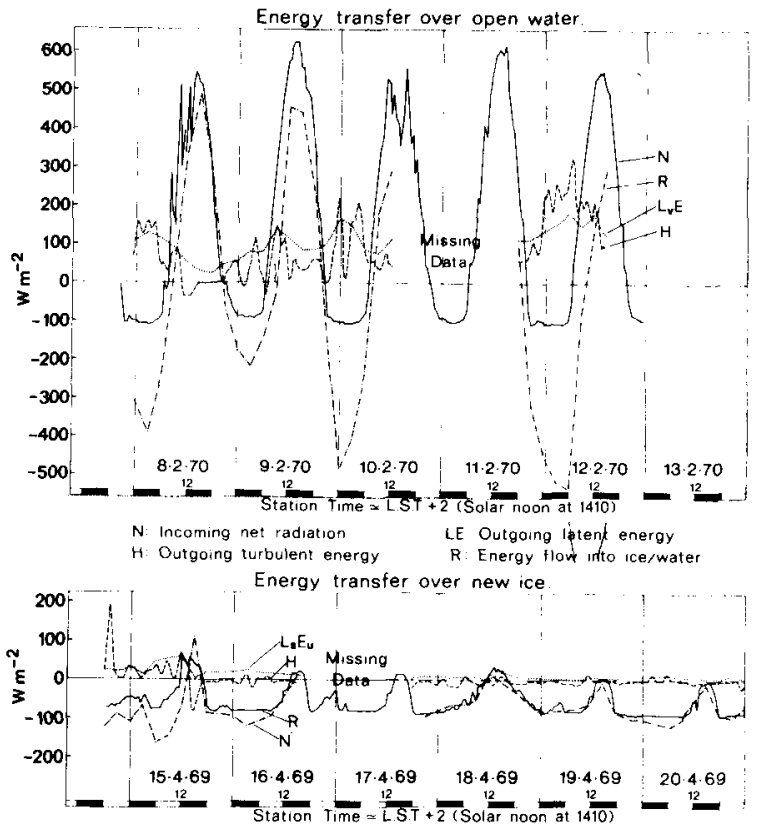

Fig.4. Energy fluxes before and after the formation of a seasonal ice cover (after Allison 1973). The ice thickness increases from $0.11 \mathrm{~m}$ on Aprif 15 to $0.28 \mathrm{~m}$ on Apri1 20.

As soon as the ice cover forms, the turbulent fluxes are drastically reduced. Figure 4 (Allison 1973) compares the energy fluxes prior to and shortly after the formation of an ice cover. The total turbulent transfer $\left(H+L_{S} E\right)$ decreases from an average of $120 \mathrm{~W} \mathrm{~m}^{-2}$ before freeze-up to $40 \mathrm{~W} \mathrm{~m}^{-2}$ over $0.15 \mathrm{~m}$ thick ice, and the strong diurnal variation in the heat loss from the water is damped by the ice. Note 
that the turbulent fluxes over open water were measured more than one month before freeze-up and would be expected to be even greater immediately before the ice forms. The total turbulent loss decreases further as the ice thickens (Fig.4). Maykut (1978) stresses the importance of heat loss from thin ice: his model shows that nearly twice as much turbulent heat is lost in autumn from ice $0.05 \mathrm{~m}$ thick than from $0.40 \mathrm{~m}$ ice and that in winter the thin ice is relatively much more important.

Initially, conditions above the ice are unstable and the thin ice loses heat, but by the end of April, when the ice thickness is $0.5 \mathrm{~m}$, a surface inversion develops and the surface gains sensible heat. During the mid-winter months, the latent heat transfer can also be towards the surface, with a resulting frost deposit (Weller 1968). Although the turbulent heat exchange varies somewhat from year to year, the mean total turbulent energy gained by the sea ice seldom exceeds $20 \mathrm{~W} \mathrm{~m}^{-2}$. The average wind speeds at Mawson are in excess of $10 \mathrm{~m} \mathrm{~s}^{-1}$.

By october, the ice surface is ablating and the latent heat transfer is away from the surface, and between early and mid-November, unstable conditions develop and the sensible heat transfer is also away from the ice. The total turbulent heat loss increases slightly towards mid-summer but is usually less than $30 \mathrm{~W} \mathrm{~m}^{-2}$. With final break-out of the sea-ice cover the direction of the sensible heat flux may reverse yet again (Fig.2), but because of evaporation, the total turbulent fiux is still away from the water. The most marked initial effect of ice break-out on the turbulent fluxes is an increase in diurnal variability.

\section{ENERGY FLUXES WITHIN THE ICE}

In late March, the total heat lost by open water can exceed $200 \mathrm{~W} \mathrm{~m}^{-2}$ and the fluxes show a strong diurnal variation. The insulating ice cover reduces this loss and, while the heat conducted through thin ice is fairly high, it quickly decreases from $75 \mathrm{~W} \mathrm{~m} \mathrm{~m}^{-2}$ in $0.2 \mathrm{~m}$ thick ice to typical winter-ice values of $30 \mathrm{~W} \mathrm{~m}^{-2}$

Heat flux within the ice includes penetration of short-wave radiation, but the effect of this remains smal1 until the beginning of Dctober. Winter temperature profiles within the ice are essentially linear and conduction is the dominant flux. From october, the temperature profiles develop considerable curvature due to heating by absorption of radiation in the upper ice layers. Weller and Schwerdtfeger (1967) discuss radiation penetration into the ice in more detail, but it should be noted that al though the conducted heat flux at the top surface may increase to as much as $100 \mathrm{~W} \mathrm{~m}^{-2}$ in November and December, most of this is supplied by the absorbed short-wave radiation. The total resultant heat flux through the ice surface $\left(B_{u}+I_{u}\right)$ is small and, as the bulk of the ice becomes waterlogged and rotten, the ice becomes isothermal.

\section{SURFACE ENERGY BALANCE: SUMMARY}

From the above discussions of the individual fluxes we can summarize the points of importance for the overall energy balance. In autumn, before freezeup, the major loss of heat by the water body is due to the turbulent fluxes in the atmosphere, al though late in the season the net radiative loss is also important. When the ice forms, the turbulent fluxes are greatly reduced but the radiative loss is little changed. As the ice grows, the direction of the turbulent flux reverses and the winter loss of net radiation is balanced partly by this, but more importantly, by the flux of heat through the ice from the water underneath. In late spring and summer, the total flux from within the ice decreases and the surface also has a net radiative gain: this incoming energy is balanced by turbulent heat losses. When the ice cover breaks-out, the net radiative gain increases markedly because of the large albedo decrease at a time of high incoming short-wave radiation. Finally, in midsummer the open water gains heat, predominantly by net radiation but also by sensible heat, before starting another cooling cycle about early February.

\section{ENERGY BALANCE AND INTERACTIONS AT THE ICE-OCEAN} INTERFACE

Heat conduction away from the lower boundary decreases as the ice thickness increases and is balanced not only by latent heat released as the ice grows but also by a significant sensible heat flux from the ocean. This oceanic heat flux has a mean over the total period of ice cover of around 10-15 $\mathrm{W} \mathrm{m}^{-2}$, considerably higher than beneath Arctic ice, and it also shows strong seasonal variation.

Allison (1981) estimated the ocean heat flux for a number of years at the Mawson site as a residual in the energy balance at the lower boundary of the ice. The flux was almost always from the ocean to the ice. Initially, when the ice is thin and growing rapidly, the oceanic flux is large $\left(40 \mathrm{~W} \mathrm{~m}^{-2}\right.$ or more), but this value reduces to $10 \mathrm{~W} \mathrm{~m}^{-2}$ or less as the growth rate decreases. It is thought that the oceanic flux is largely controlled by thermohaline convection set up by salt rejected during ice growth.

The full results of temperature and salinity profiles measured beneath the ice cover will be discussed elsewhere, but Figure 5 shows profiles measured in the latter part of the year as the bottom
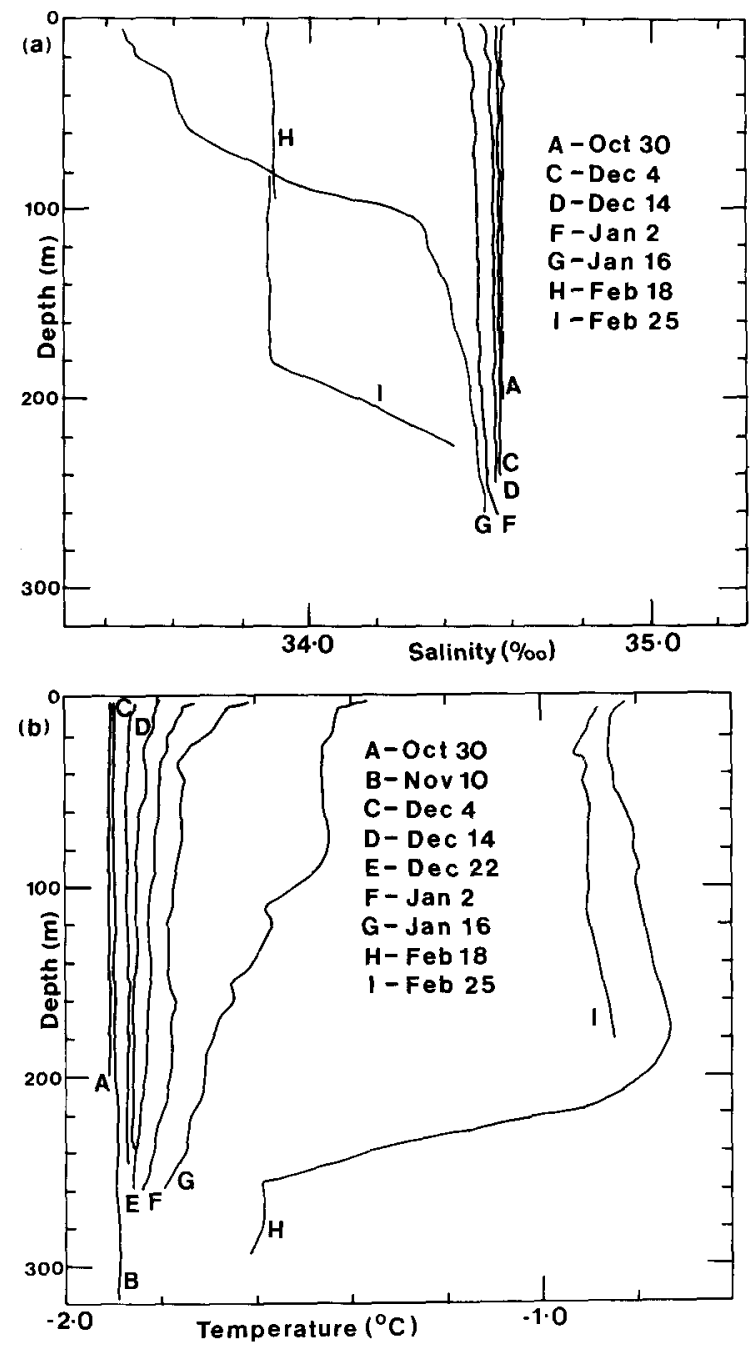

Fig.5. Salinity and water teinperature profiles under melting sea ice, Mawson, 1980-81. 
of the ice starts to melt. The slight decrease in salinity of the water column that occurs prior to December is explained completely by the melting that occurs at the underside of the sea ice (salinity $4 \%$ ), but from December, there is a significant input of fresh-water melt from the nearby ice plateau. This reaches a maximum in early January and forms a shallow surface layer (profile G) which is only mixed to the full depth of the halocline after the ice breaks out (profiles $H$ and I). Salinity profiles change little after the end of January, when the ice cover has gone and plateau melt ceased. Salt rejected from the next season's ice cover would only be sufficient to replace $45 \%$ of the depletion between profiles $A$ and $H$, implying an advection of saltier water into the region under the ice cover.

Al though there is considerable fresh-water input into the ocean, it has 1ittle effect on the ocean heat balance. If the fresh melt is assumed to be at $0^{\circ} \mathrm{C}$, then an input sufficient to give the salinity decrease between 0ctober 30 and January 2 (Fig.5(a)) would only add enough heat to give less than $1 \%$ of the temperature increase observed over the same period (Fig.5(b)). Even the large fresh-water input in early January only accounts for $10 \%$ of the temperature rise for that period.

From the temperature profiles of Figure $5(\mathrm{~b})$, we can calculate the energy gain of the water to the depth of the bottom of the summer thermocline. This increases steadily from about $80 \mathrm{~kJ} \mathrm{~m}^{-2} \mathrm{~d}^{-1}$ at the beginning of November to over $1000 \mathrm{~kJ} \mathrm{~m}^{-2} \mathrm{~d}^{-1}$ in early January $\left(100 \mathrm{~kJ} \mathrm{~m}^{-2} \mathrm{~d}^{-1}\right.$ is equivalent to a surface exchange of $\left.1.2 \mathrm{~W} \mathrm{~m}^{-2}\right)$. Together with the heat supplied by the ocean to the underside of the ice (about $5 \mathrm{~W} \mathrm{~m}^{-2}$ at this time of the year (Allison 1981), it again implies an advection into the region. The increase in advected heat later in the season is possibly due to increased atmosphere-ocean heat exchange further north as the pack-ice boundary recedes. After ice break-out, the water temperature increases to just above $0^{\circ} \mathrm{C}$ in early February (not shown in Figure 5). This requires a total heat input of $11 \mathrm{MJ} \mathrm{m}^{-2} \mathrm{~d}^{-1}$, or a surface flux of $125 \mathrm{~W} \mathrm{~m}^{-2}$. The subsequent water temperature decrease between early and late February requires a heat loss of $9 \mathrm{MJ} \mathrm{m}^{-2} \mathrm{~d}^{-1}$ or $100 \mathrm{~W} \mathrm{~m}^{-2}$.

These results, and the preliminary assessment from the profiles of the processes in the water, agree with our results from the surface heat-budget studies.

\section{REFERENCES}

Ackley SF 1981 A review of sea-ice weather relationships in the southern hemisphere. International Association of Hydrological Sciences Publication 131 (Symposium at Canberra 1979 - Sea level, ice and climatic change): 127-159

Allison I 1973 A sample study of the energy fluxes preceding and accompanying the formation of Antarctic sea ice. In Orvig $S(e d)$ Energy fluxes over polar surfaces. Proceedings of the... Symposium ... 1971. Geneva, World Meteorological Organization: $115-132$

Allison I 1981 Antarctic sea ice growth and oceanic heat flux. International Association of Hydrological Sciences Publication 131 (Symposium at Canberra 1979 - Sea level, ice and cimatic change): 161-170

Allison I, Akerman G 1980 Sea ice and ocean energy balance studies at Mawson, Antarctica. International Association of Hydrological sciences Publication 124 (Symposium at Seattle 1977 - Sea Ice Processes and Models): 347-359

Allison I, Morrissy $J \mathrm{~V}$ In press. Automatic meteorological stations and data buoys in the Antarctic - recent Australian experience. Australicon Meteorological Magazine
Andreas E L 1980 Estimation of heat and mass fluxes over Arctic leads. Monthly Weather Review 108(12): 2057-2063

Andreas $E$ L, Ackley S F In press. On the differences in ablation seasons of Arctic and Antarctic sea ice. Joumal of the Atmospheric Sciences

Andreas $E L$, Paulson C A, Williams $R M$, Lindsay $R W$, Businger J A 1979 The turbulent heat flux from Arctic leads. Boundary Layer Meteorology 17: 57-91

Hibler W D III 1980 Modeling a variable thickness sea ice cover. Monthly Weather Review 108(12): 1943-1973

Holmgren $B$, weller $G 1974$ Local radiation fluxes over open and freezing leads in the polar pack ice. AIDJEX Buzletin 27: 149-166

Langleben M P 1969 Albedo and degree of puddling of a melting cover of sea ice. Joumal of Glaciology 8(54): 407-412

Maykut G A 1978 Energy exchange over young sea ice in the central Arctic. Joumal of Geophysical Research 83(C7): 3646-3658

Parkinson C L, Washington W M 1979 A large-scale numerical model of sea ice. Joumal of Geophysical Research 84(C1): 311-337

Weller G 1968 Heat-energy transfer through a fourlayer system: air, snow, sea ics, sea water. Journal of Geophysical Research 73(4): 1209-1220

Weller G 1972 Radiation flux investigation. AIDJEX BuZZetin 14: 28-30

Weller G 1980 Spatial and temporal variations in the south polar energy balance. Monthzy weather Review 108(12): 2006-2014

weller G, Schwerdtfeger P 1967 Radiation penetration in Antarctic plateau and sea ice. In Polar meteorology. Proceedings of the WMO/SCAR/ ICPM Symposium... Geneva... 1966: 120-141 (WMO Technica! Note 87 ) 